\title{
Venous $\mathrm{pH}$ can safely replace arterial $\mathrm{pH}$ in the initial evaluation of patients in the emergency department
}

\author{
A-M Kelly, R McAlpine, E Kyle
}

\begin{abstract}
Objective-This study aims to determine the extent of correlation of arterial and venous $\mathrm{pH}$ with a view to identifying whether venous samples can be used as an alternative to arterial values in the clinical management of selected patients in the emergency department.

Methods-This prospective study of patients who were deemed by their treating doctor to require an arterial blood gas analysis to determine their ventilatory or acid-base status, compared $\mathrm{pH}$ on an arterial and a venous sample taken as close to simultaneously as possible. Data were analysed using Pearson correlation and bias (Bland-Altman) methods.

Results-Two hundred and forty six patients were entered into the study; 196 with acute respiratory disease and 50 with suspected metabolic derangement. The values of $\mathrm{pH}$ on arterial and venous samples were highly correlated $(r=0.92)$ with an average difference between the samples of -0.4 units. There was also a high level of agreement between the methods with the $95 \%$ limits of agreement being -0.11 to +0.04 units.

Conclusion-Venous $\mathrm{pH}$ estimation shows a high degree of correlation and agreement with the arterial value, with acceptably narrow $95 \%$ limits of agreement. Venous pH estimation is an acceptable substitute for arterial measurement and may reduce risks of complications both for patients and health care workers. (Emerg Med f 2001;18:340-342)
\end{abstract}

Keywords: venous $\mathrm{pH}$; blood gas analysis

Department of Emergency Medicine, Western Hospital, Private Bag, Footscray 3011, Melbourne, Australia and the University of Melbourne

Correspondence to: Professor Kelly (Anne-Maree.Kelly@) wh.org.au)

Accepted for publication 15 March 2001 risk of transmission of blood borne viruses such as hepatitis C and HIV.

Over the past several decades, a number of small studies have shown that $\mathrm{pH}$ can be accurately estimated from venous blood and "arterialised" venous blood. ${ }^{1-7}$ It has been reported that venous $\mathrm{pH}$ is almost identical to arterial pH. ${ }^{167}$ This is supported by a recent small study of patients with diabetic ketoacidosis that showed that venous blood could be substituted for arterial in the assessment of acidosis. ${ }^{8}$ Despite this evidence, arterial blood sampling remains the common method of determining acid-base status. There is no published evidence regarding the accuracy of venous $\mathrm{pH}$ measurement in the population of emergency department (ED) patients requiring assessment of their acid-base status.

This study aims to determine the extent of correlation of arterial and venous $\mathrm{pH}$ with a view to identifying whether venous samples can be used as an alternative to arterial values in the clinical management of selected patients in the ED.

\section{Methods}

This prospective study was conducted in the Emergency Department of Western Hospital, a 250 bed community teaching hospital in Melbourne, Australia. The ED has an annual census of 36000 adult patients.

Patients were eligible for entry into the study if they were deemed by their treating doctor to require an arterial blood gas analysis to determine their ventilatory or acid-base status. In practice, this limited the study to patients with respiratory or metabolic disease of a severity that warranted blood gas determination as part of assessment. After having the study explained and providing verbal consent, patients had arterial and venous blood gas samples drawn with minimum delay between the taking of samples. For patients receiving supplemental oxygen therapy, this was kept constant for the 10 minute period preceding the taking of samples. Both samples were analysed as soon as possible after collection by the same blood gas analyser. Patients were excluded if verbal consent could not be obtained. Samples were excluded, if after analysis, the sample thought to be arterial in origin proved to be venous. 


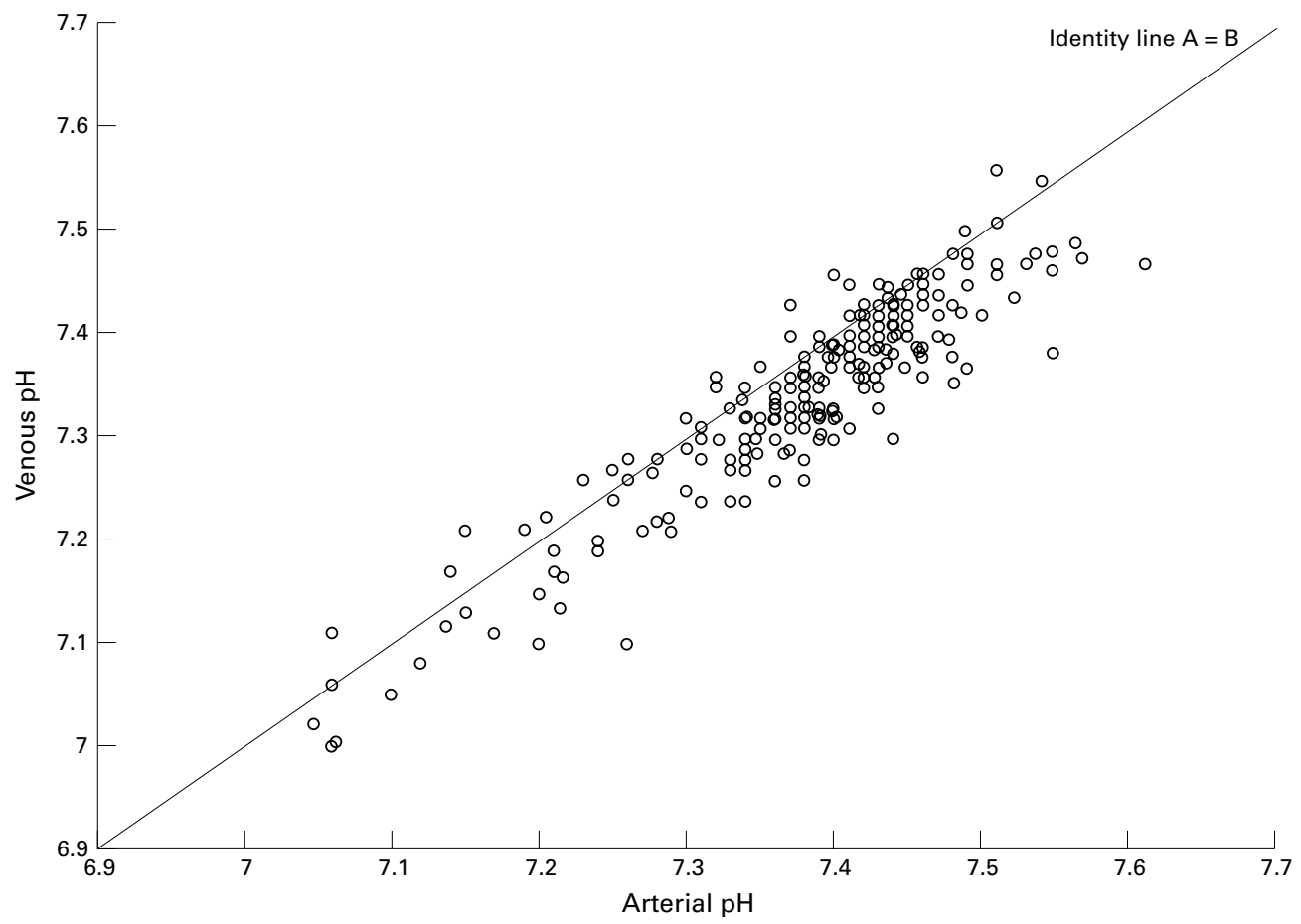

Figure 1 Correlation of arterial and venous $p H$ values.

Data were analysed using Pearson correla- tory disease and 50 with suspected metabolic tion and bias plot methods.

The study was approved by the Clinical Research and Ethics Committee. derangement.

The range of arterial blood $\mathrm{pH}$ was from 7.05 to 7.61 with a mean of 7.38 and a median of 7.40. Based on the arterial sample, 136 sam-

Results

Two hundred and forty six patients were ples were within the laboratory normal range entered into the study; 196 with acute respira(7.35-7.45). Forty three samples were alkalotic and 67 were acidotic.

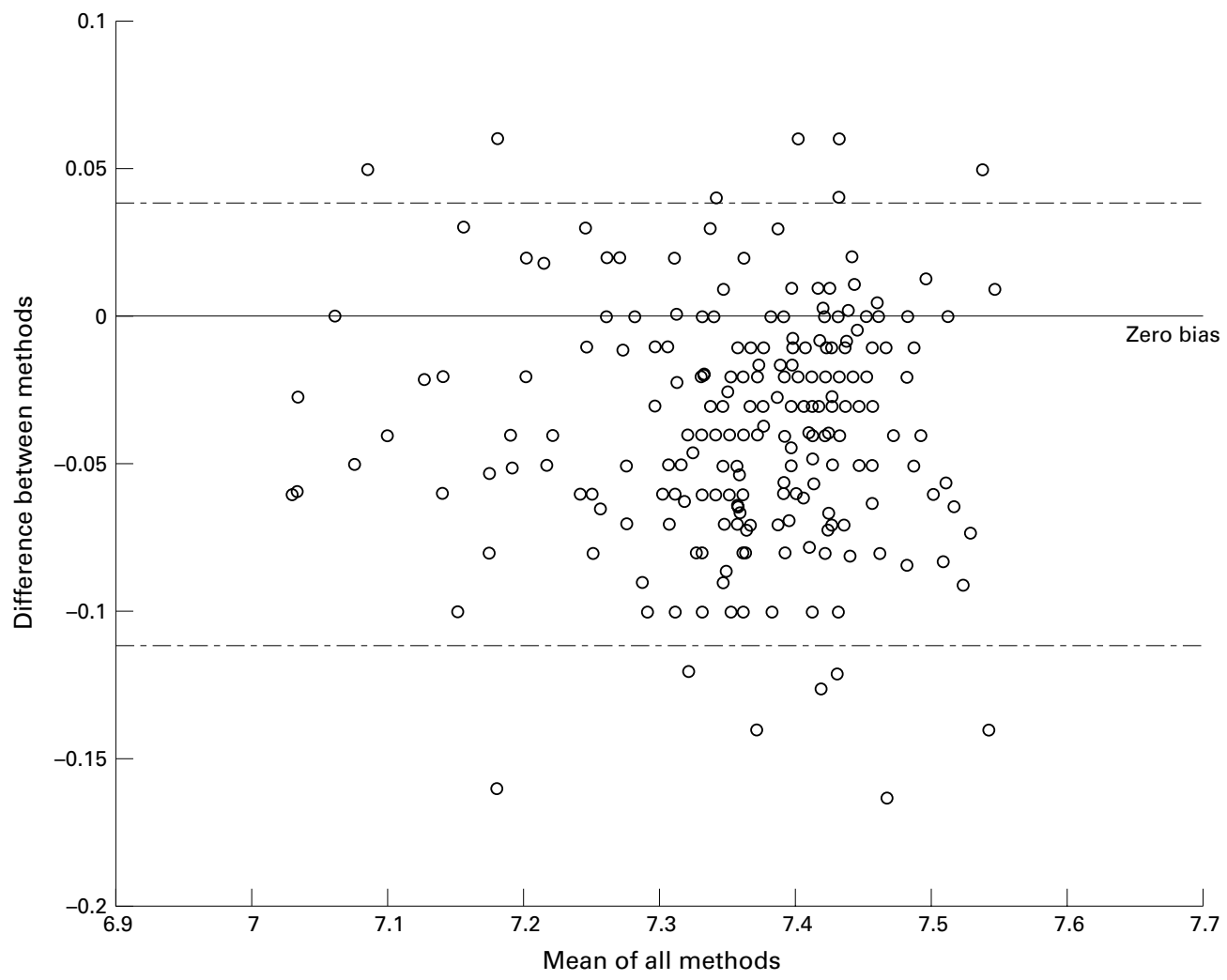

Figure 2 Bias (Bland-Altman) plot showing agreement between arterial and venous $p H$ values and $95 \%$ limits of agreement. 
The values of $\mathrm{pH}$ on arterial and venous samples were highly correlated $(r=0.92$, fig 1$)$. The difference between arterial and venous samples ranged between -0.16 to +0.06 units, with an average of -0.04 units.

Altman and Bland ${ }^{10}$ suggest that when assessing new tests it is agreement rather than correlation that is important. This can be shown visually in a bias (Bland-Altman) plot that plots the difference between the tests against an estimation of the true result of the test (assumed to be the mean of the test results). The bias plot for arterial versus venous $\mathrm{pH}$ is shown in figure 2 . This shows excellent agreement with the $95 \%$ limits of agreement being -0.11 to +0.04 units.

\section{Discussion}

Arterial blood gas analysis is the standard method for obtaining clinical acid-base assessment. Arterial sampling is however painful and carries a small risk of vascular complications for the patient. It also requires an additional vascular puncture, thus exposing staff to increased risk of needlestick injuries and blood borne infection.

A number of studies have suggested that venous $\mathrm{pH}$ measurement is in sufficient agreement with the arterial value to be an acceptable alternative..$^{1-8}$ These studies have however been small and venous $\mathrm{pH}$ estimation has not gained wide acceptance. To the authors' knowledge, this is the first large study of this question that investigates a population of patients with acute illness. Our study showed a high level of correlation and agreement. The average difference between the tests of $-0.04 \mathrm{pH}$ units is not clinically significant. Additionally, the 95\% limits of agreement $(-0.11$ to +0.04$)$ are acceptably narrow. The high level of agreement shown suggests that the venous $\mathrm{pH}$ estimation is an acceptable substitute for an arterial estimation.

This study has some limitations that should be considered when interpreting the results. The study sample was a convenience sample based on when time and resources allowed patient enrolment. This is however unlikely to have resulted in systematic bias. As less than half of the sample had abnormal $\mathrm{pH}$ values and only approximately one quarter were acidotic, it might be argued that accuracy at the extremes of the pathological $\mathrm{pH}$ range has not been tested. The range however was quite broad (7.05 to 7.61) and clinical judgement should be applied when a value of any test does not tally with the clinical picture. The study was conducted at a single institution and for practical reasons required consent to be given in English. Thus the sample is biased towards English speaking Australians and generalisability to other ethnic groups or patient populations might be in question.

In conclusion, venous $\mathrm{pH}$ estimation shows a high degree of correlation and agreement with the arterial value, with acceptably narrow $95 \%$ limits of agreement. Venous $\mathrm{pH}$ estimation is an acceptable substitute for arterial measurement and may reduce risks of complications both for patients and health care workers.

The authors would like to thank the nursing and medical staff of the Department of Emergency Medicine at Western Hospital for enrolling patients in this study and Debra Kerr for assistance with data collection and analysis.

Funding: none.

Conflicts of interest: none.

1 Gambino SR. Comparisons of $\mathrm{pH}$ in human arterial, venous and capillary blood. Am f Clin Pathol 1959;32:298-300.

2 Searcy RL, Gordon GF, Simms NM. Choice of blood for acid-base studies. [Letter]. Lancet 1963;ii:1232.

3 Long AP Jnr. Venous or arterial blood gas measurement. [Letter]. FAMA 1971;217:1706.

4 Forster HV, Dempsey JA, Thomson J, et al. Estimation of arterial $\mathrm{pO} 2, \mathrm{pCO} 2, \mathrm{pH}$ and lactate from arterialised venous blood. $\mathcal{F}$ Appl Physiol 1972;32:134-7.

5 Brooks D, Wynn V. Use of venous blood for $\mathrm{pH}$ and carbon dioxide studies. Lancet 1959;i:227-30.

6 Paine EG, Boutwell JH, Soloff LA. The reliability of arterialised venous blood for measuring arterial $\mathrm{pH}$ and $\mathrm{pCO} 2$. Am ₹ Med Sci 1961;242:431-4.

7 Gambino SR. Normal values for adult human venous plasma pH and CO2 content. Am f Clin Pathol 1959;32: 294-7.

8 Brandenburg MA, Dire DJ. Comparison of arterial and venous blood gas values in the initial emergency departvenous blood gas values in the initial emergency departEmerg Med 1998;31:459-65.

9 Bland JM, Altman DG. Statistical methods for assessing agreement between two methods of clinical measurement. Lancet 1986;i: 307-10

10 Bland JM, Altman DG. Comparing methods of measurement: why plotting difference against standard method is misleading. Lancet 1995;346:1085-7. 